\title{
Improving the Energy Performances of the Refrigeration Systems with Subcooling Using the Eco-Friendly Refrigerant R600a: Initial Experimental Results
}

\author{
Edison Gundabattini ${ }^{1}$, Claudia Masselli ${ }^{*}$, Darius S. Gnanaraj ${ }^{3}$, Sohith Tadikonda ${ }^{4}$, Vikram Karnati ${ }^{4}$, Vamsi Krishna \\ Vemireddy ${ }^{4}$ \\ ${ }^{1}$ Department of Thermal \& Energy Engineering, Vellore Institute of Technology (VIT), Vellore, Tamil Nadu 632014, India \\ ${ }^{2}$ Department of Industrial Engineering, University of Salerno, Via Giovanni Paolo II 132, 84084, Fisciano (SA), Italy \\ ${ }^{3}$ Department of Design \& Automation, Vellore Institute of Technology (VIT), Vellore, Tamil Nadu 632014, India \\ ${ }^{4}$ School of Mechanical Engineering, Vellore Institute of Technology (VIT), Vellore, Tamil Nadu 632014, India
}

Corresponding Author Email: cmasselli@unisa.it

https://doi.org/10.18280/i2m.190201

Received: 9 November 2019

Accepted: 10 February 2020

\section{Keywords:}

refrigeration, R134a, R600a, hydrocarbons, subcooling, drop-in, cooling systems, GWP

\begin{abstract}
In this paper the attention is focused on introducing the initial experimental results of a comparative experimental investigation on the energy performances of R600a tested as drop-in of $\mathrm{R} 134 \mathrm{a}$ in a test-bench refrigeration system developed at the School of Mechanical Engineering of VIT University located in Vellore (India). Moreover, a comparison of the energy performances was pursued also with the system working with and without sub-cooling. The initial experimental investigation is performed respecting the requirement that the two fluids occupy the same volume. The initial energy performances are carried out in terms of evaporator temperature, coefficient of performance and refrigeration effect. The effect of drop-in with R600 a system previously working with R134a, carries an enhancement of the energy performances in terms of COP and refrigeration effect. Moreover, subcooling carries to an additional benefit on the refrigeration effect. The introduced initial experimental results constitute just the first step of a bigger investigation to be conducted in India, focused on analyzing the impact of the drop-in of HFC with new eco-friendly refrigerants.
\end{abstract}

\section{INTRODUCTION}

Nowadays, global warming is a shared worldwide problem: the human end contributed significantly in the last half century to its intensification, since the energy consumption is considered among the main reasons to temperature increment in our world. The warning signals launched by our planet are already worrying and all the world is called to responsibility to avoid the catastrophic consequences that could occur. All the most critical sectors for energy consumption are called to adopt countermeasures to counteract the progress of global warming. Among them, more than $20 \%$ of the worldwide energy consumption originates from the sector identified by refrigeration, air conditioning and heat pumping. Almost the totality of the cooling systems is based on Vapor Compression (VC) and therefore on fluid refrigerants. Since the beginning of the utilization of VC-based systems and up to a couple of decades ago, the benchmark refrigerants were ChloroFluoroCarbons (CFCs) and HydroChloroFluoroCarbons (HCFCs) due of high Ozone Depletion Potential (ODP) and Global Warming Potential (GWP) [1]. They were the cause of the CFCs and HCFCs banning by the Montreal Protocol [2] that took place in 1987 to the purpose of protecting the stratospheric ozone layer. Over the years subsequent measures were taken in 1997 with Kyoto Protocol [3], an international agreement linked to the United Nations Framework Convention on Climate Change. Because of their significant Ozone Depletion Potential (ODP), the usage of $\mathrm{HCFC}$ has been forbidden since 2000 and the only fluorinated class of allowed refrigerant was the HydroFluoroCarbons (HFCs), characterized by no ODP but consistent GWP [4-7].

Since then, periodical meetings among the Parties agreeing to the Montreal Protocol have been succeeding over the year modifying and adapting the measures approved to counteract the global warming and, more generally, preserve the ecosystem. From 2009, a progressive phasing out of HFCs has been established, in order to reduce greenhouse gases emissions. The 28th Meeting of the Parties (MOP28) [8] to the Montreal Protocol which was held in Kigali, Rwanda, from October 10 to 14,2016 , led to an international agreement on the phase-down of the production and consumption of HFCs. Specifically, the Kigali amendment identifies the countries composing the Article 5 as the 136 primarily developing countries as specified by Montreal Protocol, except for ten countries: Bahrain, India, Iran, Kuwait, Oman, Pakistan, Qatar, Saudi Arabia and the United Arab Emirates. These ten countries constitute a separate group of Article 5 countries (group II), because they are characterized by elevate ambient air temperature and therefore, they are particularly dependent by air conditioning. All the other countries (the "developed" countries) are classified are non-Article 5 parties [9]. The Kigali amendment represents a milestone agreement that prescribes a gradual $80 \%$ to $85 \%$ phase-out of HFC at the end of 2040s with a staggered execution of consumption freezers from: 2019 for non-Article 5 countries (the "developed" countries); 2024 for most of the "developing" countries (Article-5 group I); 2028 for the other ten "developing" countries (Article-5 group II). Basing on above prescriptions, 
European countries already banned HFCs, following EU regulation 517/2014, which contains a number of prescriptions about the phase-out of products and equipment containing fluorinated greenhouse gases. The rest of the all-over-theworld countries agreeing to the Kigali amendment is approaching to do the same.

Therefore, in the last decade, the phasing out of fluorinated greenhouse gases is a topic that has increasingly involved the scientific community and world research, whose efforts are nowadays focused on development of new low-GWP and noODP refrigerants to be employed [10], as well as part of the community targeted their interest in developing new refrigeration technologies as the class of caloric cooling ones [11-14], characterized by zero-GWP solid-state refrigerants [15].

Stemming the above scenario, also the primarily developing countries are playing an active part in the phase out of fluorinated greenhouse gases, following mostly the research routes that are already travelling the developed countries. To this hope the paper aims to focus on the problem of phasing out of HFC in India an Article-5 group II primarily developing country. As a matter of fact, India is now approaching to the problem of phasing out of the refrigerants. Until now in India the commonly used refrigerants were HFCs therefore, Indian scientists and researchers are orienting their studies on the drop-in issue with some delay compared to European countries.

The common policies used to increase the energy efficiency of cooling systems are the research and development of energy-efficient refrigerants and the conversion of system components. The research for novel fluids must follow the prerequisites of identifying not ozone depleting and low GWP fluids $[16,17]$. This topic has thus become a major challenge.

Two are the lines in such choice: from one side, a new generation of synthetic fluids that is constituted by Hydrofluoroolefins (HFOs) [18]; on the other side there are natural fluids, especially HydroCarbons (HC), like propane, butane, isobutene and isobutene mixtures considered [19] as environmental benevolent refrigerants. These refrigerants have zero ODP and very small GWP which guarantee a very short lifetime once released in the atmosphere [20-22]. The current worldwide state of the art reveals that the HFOs have been tested as drop-in replacement of domestic refrigerators previously operating with HFC134a [23-26] and this constitutes a really point of favor in the usage of this fluids.

Among HFOs, which derive from olefins rather than alkanes, there are two hopeful ones: HFO1234yf [27] and HFO1234ze [28]. These two recently introduced environment friendly HFO refrigerants show GWP minor than 6 and their thermo-physical characteristics are comparable to the ones of to HFC134a. On the other side, recent investigations perpetuated by Navarro et al. [29] revealed that the HFC134a drop-in with HFO1234yf and HFO1234ze carries to a COP reduction, respectively, $5-30 \%$ and $2-8 \%$ than $\mathrm{HFC} 134 \mathrm{a}$.

Other studies have taken the attention on the drop-in with HFC/HFO mixture: Mota-Babiloni et al., that summarized this aspect in their work [30], observed that the HFC134a drop-in with HFC134a/HFO mixtures carries to an average COP decrement around $6 \%$ whereas the HFC404a replacement with their HFO-binary mixtures, carries up to a $21 \%$ reduction of the cooling capacity [31]. Among the HFC134a/HFO binary mixtures, R450A was identified as a promising option for HFC134a drop-in [32].

Intensive studies on suitable alternative refrigerants for vapor compression systems have persisted [33-35] over the years also among the fluids named as natural. The term "natural refrigerants" means all those substances or compounds that can be found directly in nature or whose composition does not occur by chemical synthesis. They are substances that have a low environmental impact by not containing chlorine or fluorine. Ammonia, carbon dioxide, hydrocarbons and water are natural refrigerants. Hydrocarbons are organic compounds, mainly of fossil origin, composed only of carbon and hydrogen atoms. They have good thermodynamic properties, including high enthalpy changes that allows a lower refrigerant charge. In terms of efficiency, they can compete with HFCs and HCFCs, reaching high COP values in most applications. Among the advantages of hydrocarbons there is compatibility with many lubricants used in the equipment with the exception of those containing silicone and silicates $[36,37]$. They are also used in mixtures (together, for example, with HFCs), allowing an easier retrofit operation of plants loaded with CFCs. They have a low environmental impact, are not toxic but are highly flammable belonging to the A3 safety class. For this reason, they have limitations on use in terms of the quantities allowed in the equipment but by the regulation of the charge can minimize the risk factors due to flammability. Indeed, in a design of a system that employs hydrocarbon as the working fluid, it is mandatory to use the lowest possible refrigerant charge without worsening the overall energy efficiency for both safety and environmental reasons. Therefore, refrigerant charge reduction is a key aspect among the latest investigations [38-40]. Hydrocarbons such as propane and isobutene find application in the refrigeration sector, while other hydrocarbons are used as alternative foaming agents in the production of foams. As HFOs also propane, Iso-butane, mixtures of hydrocarbons can be made as the replacement of HFC134a [41, 42].

The employment of hydrocarbons could represent a longterm answer to the problems of both global warming and ozone layer depletion [43, 44].

R600a can be used as direct drop-in replacement in refrigerating equipment previously working with R134a. Table 1 lists the thermodynamic properties and the characteristics related to environmental compatibility and safety, compared with the ones of R134a. R600a presents a very low GWP and a low boiling point as well as R134a, even if a bit higher. The critical pressures of R134a and R600a are quite similar. Moreover, it presents a large amount of latent heat of vaporization. These characteristics make it suitable for household applications. On the other side attention should be paid on safety class that for R600a is A3 whereas for R134a is A1. This means that whereas $\mathrm{R} 134 \mathrm{a}$ is a refrigerant which does not propagate non-flammable refrigerants which do not propagate the flame at atmospheric pressure and at temperature $\mathrm{T}=21^{\circ} \mathrm{C}, \mathrm{R} 600 \mathrm{a}$ belongs to the highly flammable refrigerants due of a flammability limit less than or equal to $0.10 \mathrm{~kg} \cdot \mathrm{m}^{-3}$ at a temperature of $21^{\circ} \mathrm{C}$ at atmospheric pressure, and a combustion heat of less than $19 \mathrm{~kJ}^{\mathrm{kg}} \mathrm{kg}^{-1}$.

Agrawal et al. [45] tested domestic refrigerator, previously working with R134a, dropping in R290/R600a Zeotropic blends. To find the optimum charge, they conducted experiments under various charge conditions under constant load conditions. The optimum charge was measured as $60 \mathrm{~g}$ with R290/R300a (50/50\%) zeotropic blend. The lowest temperature recorded was $-3.5^{\circ} \mathrm{C}$. In 2017 Sanchez et al. [46] carried out an experimental analysis to compare different HCs as drop-in replacement of R134a under different operating 
conditions. They observed the positive effect of working with hydrocarbons in terms of electrical power consumption. In 2019, Espíndola et al. [47] conducted an interesting experimental study on R600a evaluating the performance degradation and the generation of expansion noise. The study was approached through the employment of a household refrigerator working with isobutane contaminated with noncondensable gases. They detected that the performance degradation was due mainly to partial chocking of capillary tube that impedes the systems to reaching steady-state conditions.

Table 1. Properties of R134a and R600a

\begin{tabular}{|c|c|c|}
\hline Fluid & R134a & R600a \\
\hline Formula & $\mathrm{CH}_{2} \mathrm{FCF}_{3}$ & $\mathrm{CH}_{3}-\mathrm{CH}_{2}-\mathrm{CH}_{2}-\mathrm{CH}_{3} /$ butane \\
\hline $\begin{array}{l}\text { Molecular weight } \\
{\left[\mathrm{kg}^{*} \mathrm{kmol}^{-1}\right]}\end{array}$ & 102 & 58.12 \\
\hline Normal Boiling & & \\
\hline $\begin{array}{l}\text { Point } \\
{\left[{ }^{\circ} \mathrm{C}\right]}\end{array}$ & -26.0 & -11.6 \\
\hline $\begin{array}{c}\text { Critical T } \\
{\left[{ }^{\circ} \mathrm{C}\right]}\end{array}$ & 101.1 & 134.7 \\
\hline $\begin{array}{l}\text { Critical p } \\
\text { [bar] }\end{array}$ & 40.59 & 36.40 \\
\hline Safety Class & & \\
\hline $\begin{array}{l}\text { Max allowed } \\
\text { refrigerant } \\
\text { Charge }\end{array}$ & $\begin{array}{l}\text { A1/ } \\
\text { no limit }\end{array}$ & $\begin{array}{c}\mathrm{A} 3 / \\
0.10 \mathrm{~kg} \cdot \mathrm{m}^{-3}\end{array}$ \\
\hline GWP & 1430 & 4 \\
\hline
\end{tabular}

Next to the choice of the most suitable refrigerants with respect to the environmental compatibility, there is also the need to improve the performance of refrigeration system. This can be done by employing the method of sub-cooling [48, 49]. Generally, three are the methods to employ sub-cooling: liquid suction, dedicated and integrated ones. The integrated mechanical sub-cooler consists of only one condenser for both main and sub-cooler cycle, while dedicated sub-cooling consists of 2 separated condensers. Dedicated and integrated sub-cooling are used in moderate-to-large capacity systems. Liquid suction is done by using heat exchangers between the condenser and the evaporator. Liquid-suction sub-cooling typically used on systems with small to medium capacity, but for the household refrigerator the setup would result complex [50]. So, the other non-conventional method of sub-cooling is done by immersing the wound copper coil in water. Subcooling results in increased COP in R600a compared to $\mathrm{R} 134 \mathrm{a}$ due to the reduction of the condenser exit temperature, though increasing specific compression work due to the increase in the condensing pressure. The increase in condensing pressure was associated with the reduction of the air-refrigerant temperature difference and the refrigerant-side heat transfer coefficient once the two-phase region in the condenser is shrunken to accommodate the subcooled liquid region [51]. This leads to larger refrigeration effect and increases the performance of the system.

In this paper are introduced the initial results carried out through a test bench cooling system developed at Vellore Institute of Technology (VIT). The test bench was tested while charged with R134a and subsequently with R600a as drop in replacement. The purpose of the experimental investigation is to realize a comparative study on the energy performances of R600a tested as drop-in of R134a. Even if R600a has already been tested and adopted in other countries belonging to the developed ones, in India the study of R600a employment as
R134a drop-in represents a point of novelty and constitutes a brick to build a line of a wider Indian research on the phasing out problem, since India is one of the largest and most populous countries belonging to the Article-5 group II. To this hope the energy performances carried out from the experimental tests conducted "in-situ", at the School of Mechanical Engineering of VIT University located in Vellore (India), are presented in this paper. Furthermore the system was tested while working with and without sub-cooling for both the refrigerants, to explore also the incidence of this feature.

\section{EXPERIMENTAL APPARATUS}

The experimental apparatus consists of a simple test-bench refrigeration system developed and designed for working with both the refrigerants R134a and R600a. The two fluids experiment a refrigeration cycle with and without subcooling. Sub-cooling is done by winding the copper coil into the helical shape and by immersing it, at the outlet of the compressor, in a small tube where water flows.

A schematic diagram of the experimental apparatus is reported in Figure 1(a) whereas are reported the thermodynamic transformations are reported in: T-h diagram (Figure 1(b)); p-h diagram without subcooling (Figure 1(c)) and with the effect of subcooling (Figure 1(d)).

From Figures 1(b) (c) and (d) one can appreciate the differences between a cycle with and without subcooling. Subcooling is used for improving the cooling effect coefficient and for decreasing the compression work. As shown in Figure $1(d)$, reducing the temperature of the refrigerant at the condenser exit would be more welcome for refrigerants with large liquid specific heat and smaller latent heat of vaporization and for operating conditions with high temperature lifts. The average evaporation temperature depends also to the evaporator inlet temperature. The evaporator inlet temperature, and therefore the average evaporation temperature, change with the condensing pressure, as shown in Figure 1(d). Likewise, the average evaporation temperature also depends on the effect of subcooling.

The realized experimental setup is shown in Figure 2. Based on the refrigeration capacity of the refrigeration system a hermetic suitable compressor Tecumseh $(107 \mathrm{~W}$ and $85 \%$ as isentropic volumetric efficiency) and the other specifications of the system were selected opportunely. The design specifications of the system (evaporator size, condenser length and diameter, capillary length and diameter) are given in Table 2 to introduce the test bench cooling system developed at Vellore Institute of Technology (VIT).

In Figure 1 also the placements of the sensors, for temperature and pressure measurements, is shown. Temperature measurements are carried out through digital thermometers: Mini LCD Thermometer (accuracy $\pm 0.1^{\circ} \mathrm{C}$; working range $-50 \div 110^{\circ} \mathrm{C}$;) placed in four different points of the circuit: the evaporator at the outlet of the condenser and at the inlet and outlet of the compressor. Two are the points where pressure measurements are performed: at the inlet and outlet of the compressor, through two pressure gauges (accuracy $\pm 0.69 \mathrm{kPa}$ ). In this way the suction and discharge pressures at the compressor are monitored. The analysis of the uncertainties belonging to all the parameters deriving from directly measurements is carried out according to the method of error propagation identified by Moffat [52]. 

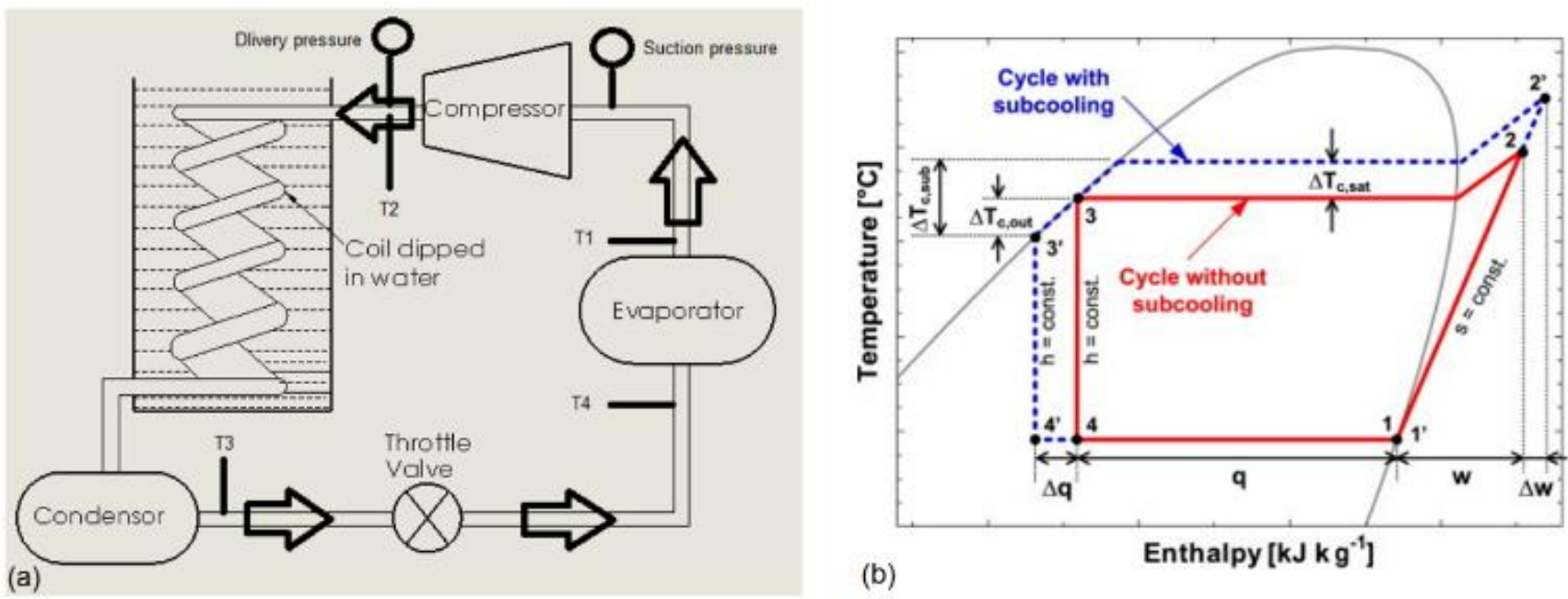

(b)

Enthalpy $\left[\mathrm{kJ} \mathrm{k} \mathrm{g}^{-1}\right]$
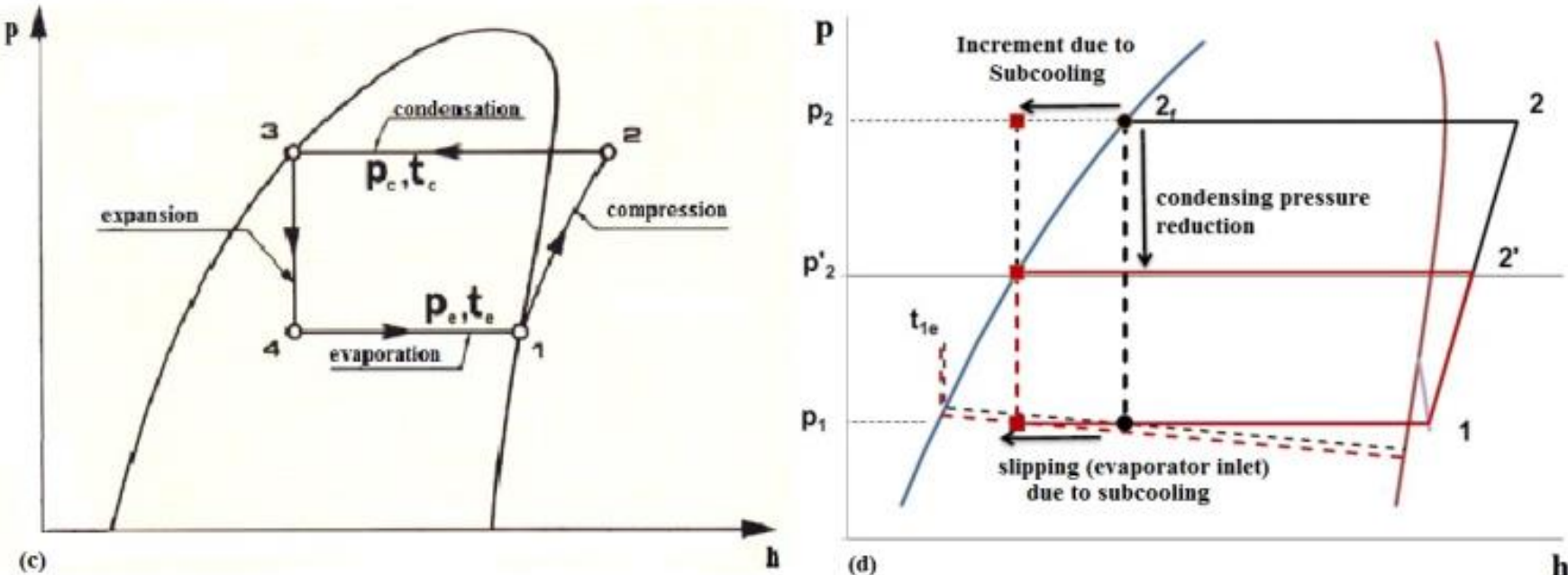

Figure 1. (a) Schematic diagram of the refrigeration system, the thermodynamic transformations in: (b) T-h diagram; (c) p-h diagram without subcooling; (d) p-h diagram with the effect of subcooling

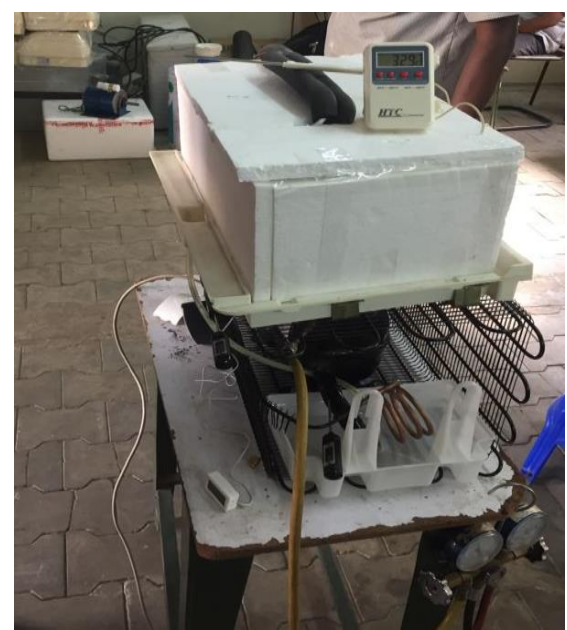

(a)

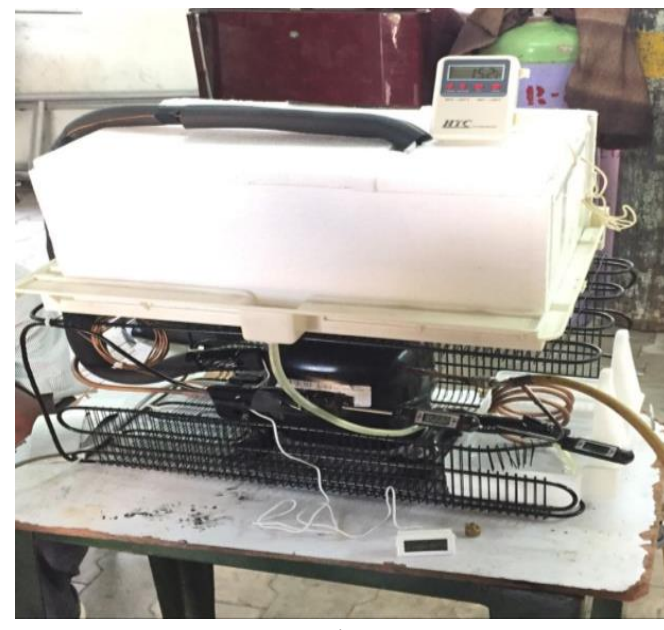

(b)

Figure 2. Experimental setup (a) side view; (b) front view

The method prescribes that a generic property $Y$, indirectly calculated from measured independent parameters $x_{i}$, could be conceived as:

$$
Y=Y\left(x_{1}, x_{2}, \ldots, x_{n}\right)
$$

Therefore, the Y accuracy could be evaluated as a function of the accuracy associated to each $x_{i}$ as:

$$
A_{y}=\left[\sum_{i=1}^{n}\left(\frac{\partial Y}{\partial x_{i}} A_{x i}\right)^{2}\right]^{1 / 2}
$$

Therefore, given the measures of pressure and temperature, the indirect evaluation through data tables carries to an accuracy of the enthalpy belonging to $\pm 1-2 \%$. 
Table 2. Design specifications of the refrigeration system

\begin{tabular}{cc}
\hline Component & Specification \\
\hline Compressor capacity & $107 \mathrm{~W}$ \\
Evaporator size & $0.0123 \mathrm{~m}^{3}$ \\
Condenser coil length & $13.91 \mathrm{~m}$ \\
Capillary length & $2.92 \mathrm{~m}$ \\
Capillary diameter & $0.90 \mathrm{~mm}$ \\
Condenser diameter & $4.76 \mathrm{~mm}$ \\
\hline
\end{tabular}

The accuracy of the coefficient of performance is evaluated as follows:

$$
\begin{gathered}
C O P=\frac{\dot{Q}_{c}}{W} \\
\frac{e_{C O P}}{C O P}=\sqrt{\left(\frac{e_{\dot{Q}_{c}}}{\dot{Q}_{c}}\right)^{2}+\left(\frac{e_{W}}{W}\right)^{2}}
\end{gathered}
$$

The same procedure is extendible to all the quantities evaluated. Basing on this the accuracy of the COP belongs to $\pm 4.5 \%$. The accuracy of the refrigeration capacity is $\pm 2.5 \%$.

\section{INITIAL EXPERIMENTAL TESTS AND RESULTS}

In order to test the affordability and the re-usability of the developed test-bench refrigeration system for many experiments and under many conditions, we deemed the first experimental investigation was to monitor the correctness of the refrigeration cycle. Indeed, in this paper are presented the results coming from a campaign of tests conducted on two different refrigerants and with the refrigeration system monitored with and without subcooling for both the refrigerants.

Specifically, the test bench was originally designed to work with R134a, in order to explore, subsequently, the possibility of working with a more environmentally friendly refrigerant, as drop-in replacement. Indeed, after the experimental testbench refrigeration setup was made, as first step, the atmosphere gas and water vapor present in the setup was removed by using a vacuum pump. Thus, with the temperature of the environment kept constant at $30^{\circ} \mathrm{C}$, the system was charged firstly with R134a and then with the eco-friendly R600a. The initial pressure of the charged refrigerants was 1 bar. The charge was made respecting the requirement that the two fluids occupy the same volume. Therefore, since under the same conditions of temperature and pressure the density of $\mathrm{R} 600 \mathrm{a}$ is smaller than the $\mathrm{R} 134 \mathrm{a}$ (as an example: with $\mathrm{p}=1$ bar and $\mathrm{T}=-26.4^{\circ} \mathrm{C}$, the density of R600a is $221 \mathrm{~kg} \mathrm{~m}^{-3}$ whereas the density of R134a is $511.9 \mathrm{~kg} \mathrm{~m}^{-3}$ ), the mass flow rate of R600a is smaller than R134a. Specifically, the system works with $0.712 \mathrm{~g} \mathrm{~s}^{-1}$ of R134a and $0.318 \mathrm{~g} \mathrm{~s}^{-1}$ of R600a. Refrigerant $\mathrm{R} 600 \mathrm{a}$ is filled in the compressor that is used, originally, for R134a.

During the working period of the apparatus, the pressure and temperature readings on pressure gauges and thermometers were taken periodically. After the experiment was completed with R134a, the system was discharged and then recharged with the eco-friendly refrigerant R600a and the same procedure was carried out. For both the refrigerants, the system was tested with and without the sub-cooling. The tests were performed in a laboratory whose environmental temperature was kept constant at $30^{\circ} \mathrm{C}$. The overall energy performances of the refrigeration system were evaluated in terms of coefficient of performance, evaporator temperature and refrigeration effect.

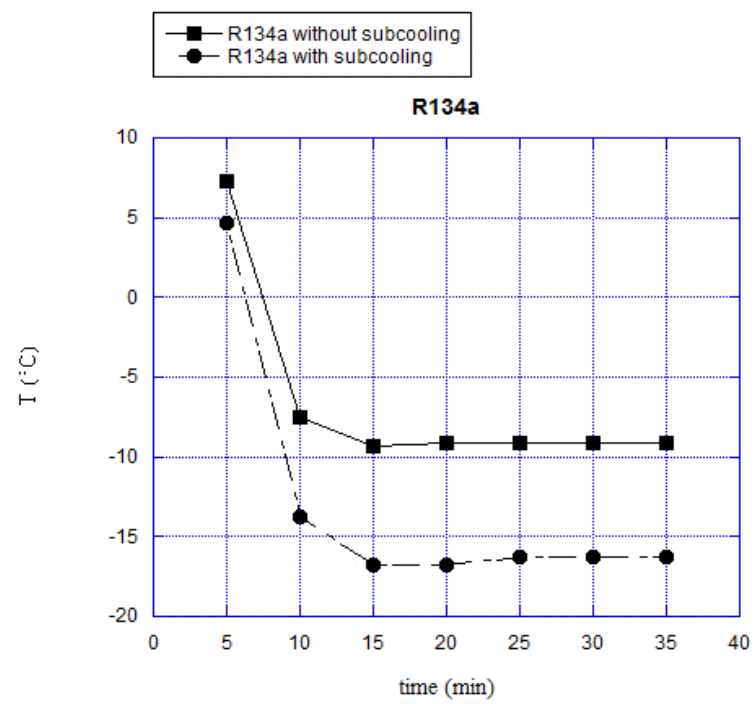

(a)

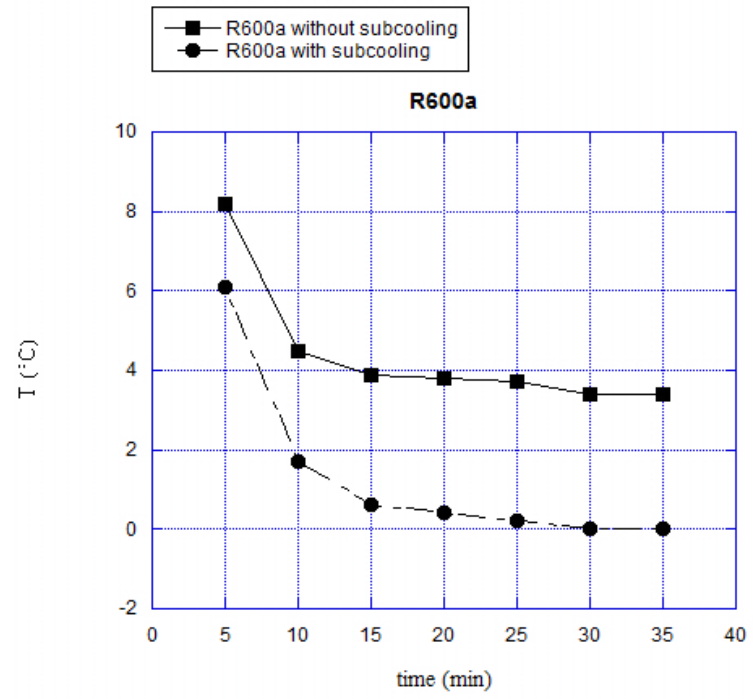

(b)

Figure 3. Evaporator temperature vs time: (a) R134a and (b)R600a with and without subcooling

Figure 3 shows the evaporator temperature measured while the system is working with R134a (Figure 3(a)) and R600a (Figure 3(b)). Given the specification of keeping the volume constant, the pressure charges are different and consequently the two refrigerants set themselves to two different steady state evaporator temperatures: $\mathrm{R} 134 \mathrm{a}$ reaches $-9^{\circ} \mathrm{C}$ and $-16^{\circ} \mathrm{C}$, while the system works respectively without and with subcooling. R600a, due to the halved mass flow with respect to $\mathrm{R} 134 \mathrm{a}$, positions the evaporator temperature around the steady-state values of $5.8^{\circ} \mathrm{C}$ and $3.7^{\circ} \mathrm{C}$, while the system works respectively without and with subcooling. Therefore, the subcooling produces a positive effect of a temperature reduction both for R134a and R600a.

In Figure 4 are reported the suction and discharge pressure trends of the system working without subcooling, charged with R134a (Figure 4(a)) and R600a (Figure 4(b)). As a matter of fact, in order to drop-in the refrigerant in the system originally working with R134a charged at 0.34 bar, to keep constant the volume, the refrigerant R600a is charged at 0.8 bar. 


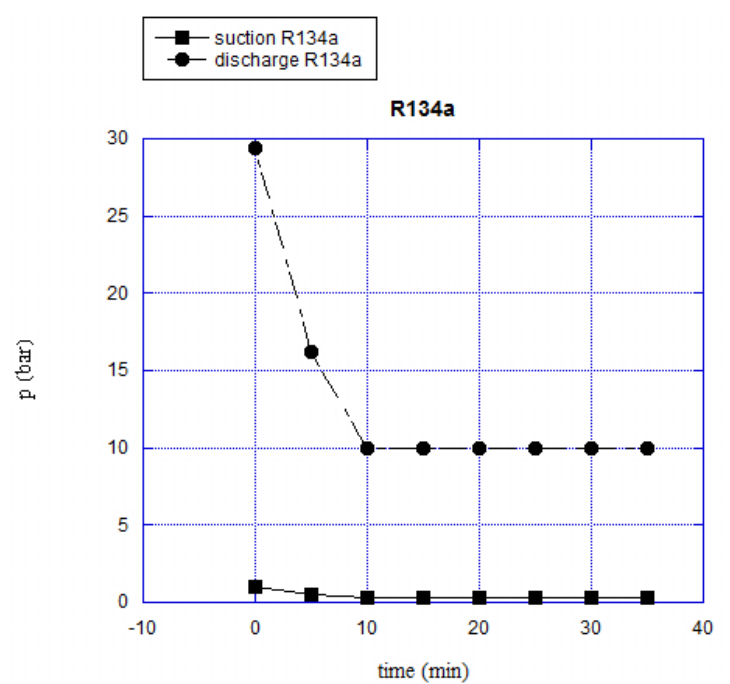

(a)

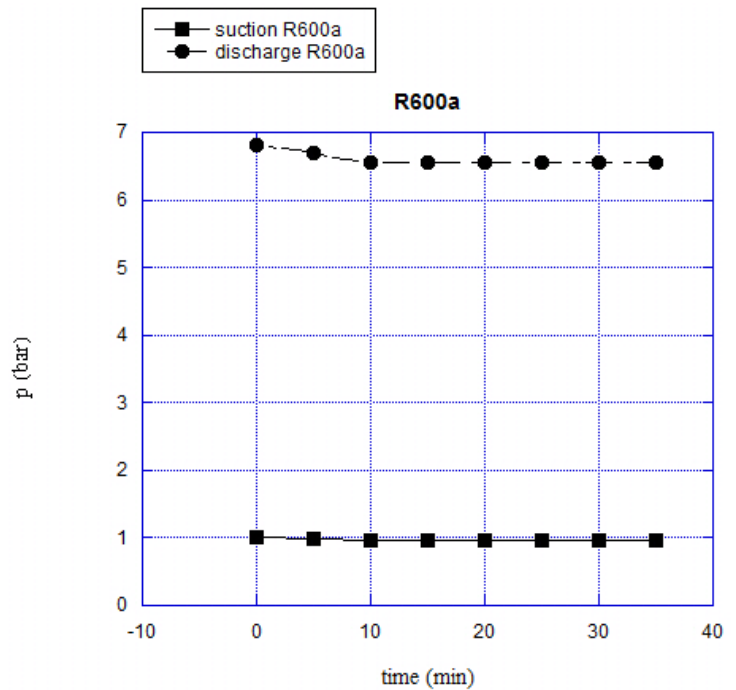

(b)

Figure 4. Suction and discharge pressure trends vs time for: (a) R134a and (b)R600a while the system works without subcooling

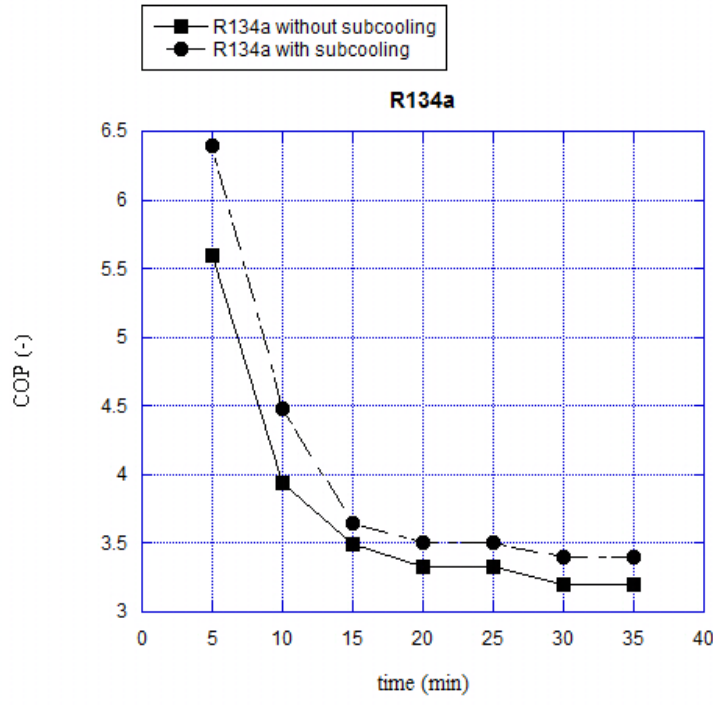

(a)

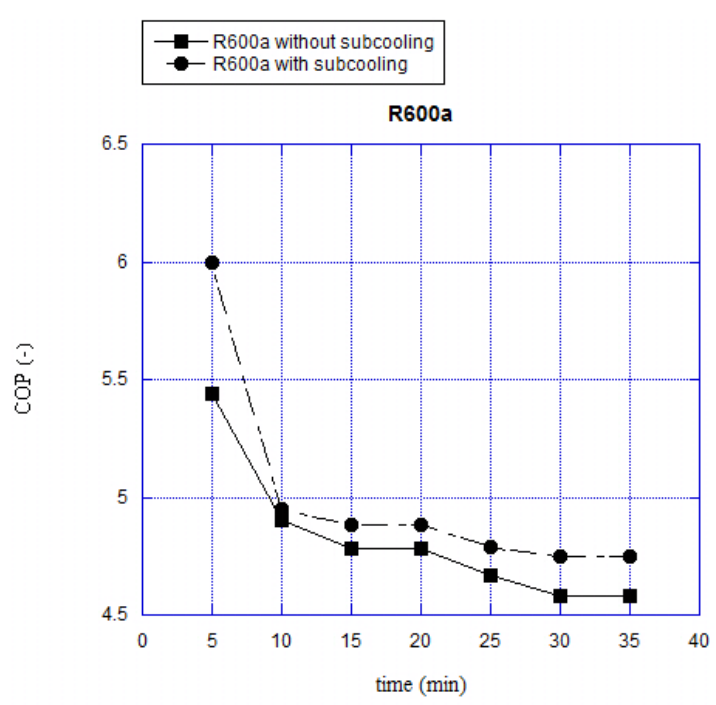

(b)

Figure 5. Coefficients of performance vs time: (a) R134a and (b)R600a with and without subcooling

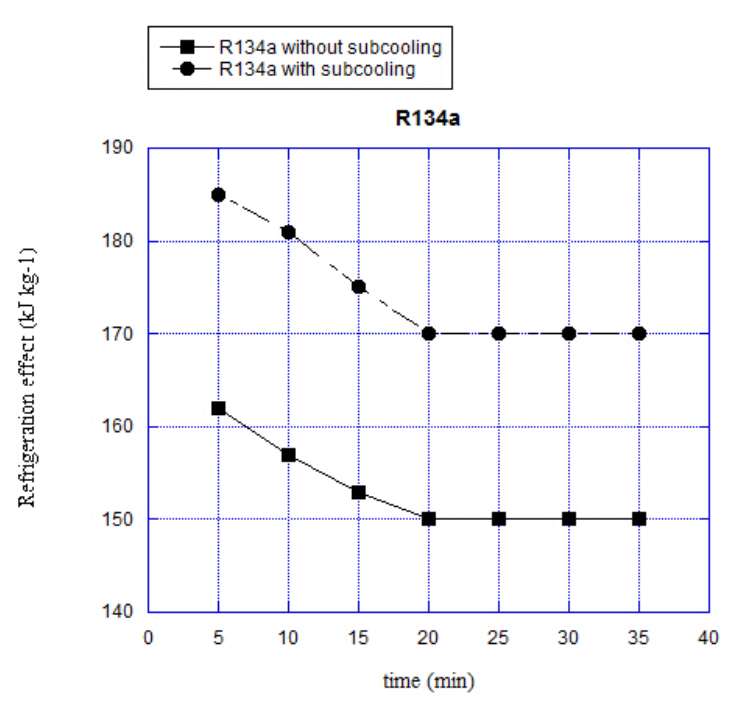

(a)

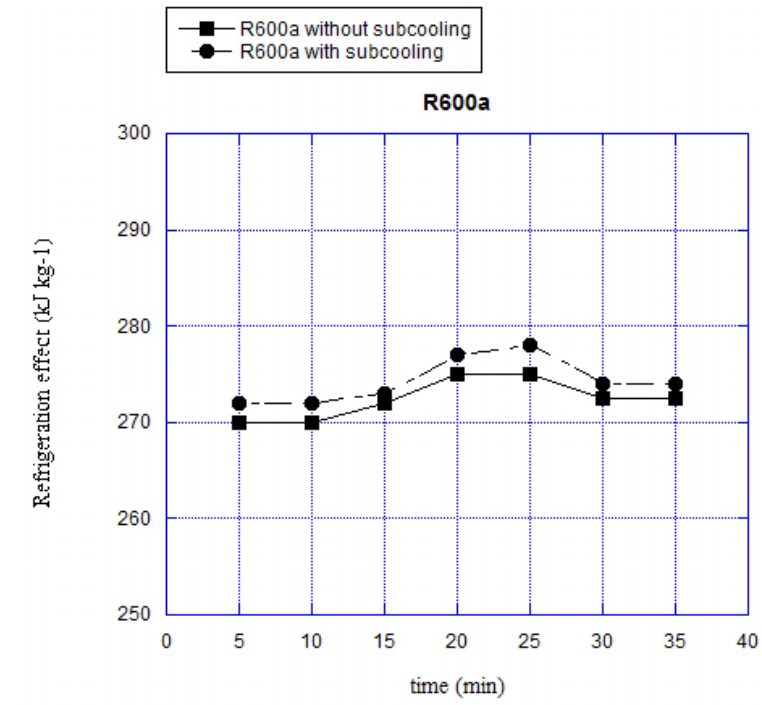

(b)

Figure 6. Refrigeration effect vs time: (a) R134a and (b)R600a with and without subcooling 
In Figure 5, is reported the Coefficient of Performance (COP) vs time, measured while the system is working with 5(a) R134a and 5(b) R600a, respectively. Without subcooling the calculated steady-state COP for R134a is approximately 3.25, whereas for R600a is 4.59. In the working conditions mentioned before, the initial experimental tests reveal that the drop-in of R134a with R600a carries to a $41.2 \%$ increment on coefficient of performance. On the other side, the effect the introduction of the subcooling carries the system reaching a steady-state COP of 3.40 for R134a and 4.80 for R600a.

Figure 6 reports the variation of refrigeration effect vs time, measured while the system is working with 6(a) R134a and 6(b) R600a, respectively. As shown in the figures, R600a gives higher refrigeration effect than R134a; this is due to the latent heat of vaporization per unit mass of refrigerant that for $\mathrm{R} 600 \mathrm{a}$ is higher than for R134a. The Refrigeration effect detected for the system charged with R600a is $+64 \%$ and $+83 \%$ higher than R134a, with sub-cooling and without subcooling, respectively. This result agrees with the results published in the scientific literature. Potker et al. assert that that for all refrigerants, as the condensing temperature increases and approaches the critical point, the liquid specific heat becomes higher and the latent heat of vaporization decreases, which subsequently increases the refrigerating effect gain [51].

\section{CONCLUSIONS}

A test-bench refrigeration system was developed, and the primary objective of the experimental investigation was to carry out initial experimental results to monitor the apparatus working with two different refrigerants: R134a and R600a. The initial experimental investigation was performed respecting the requirement that the two fluids occupy the same volume. The initial energy performances were carried out in terms of evaporator temperature, coefficient of performance and refrigeration effect. The different refrigerants flow rate, as expected, carry to different steady-state evaporator temperatures but, for both the fluids, the effect of subcooling has a benefit on this parameter. The drop-in of R134a with R600a carries to a $+41.2 \%$ mean increment on coefficient of performance and the effect the introduction of the subcooling carried a modest further benefit in COP increasing for both the fluids. Finally, the refrigeration effect detected for the system charged with R600a is $+64 \%$ and $+83 \%$ higher than R134a, with sub-cooling and without sub-cooling, respectively. The introduced initial experimental results constitute just the first step of a global investigation focused on analyzing the effect of the drop-in of HFC with new eco-friendly refrigerants, to be conducted "in-situ", at the School of Mechanical Engineering of VIT University located in Vellore (India), a "developing" country adhering to Kigali amendment. Indeed, as previously specified, this is just an initial investigation conducted in order to verify the correctness of the refrigeration cycle originally designed for working with R134a and to explore, subsequently, the possibility of working with a more environmentally friendly refrigerant, as drop-in replacement. Further investigations are planned to be conducted to provide a wider comparison under other conditions: keeping constant the mass flow rates of the refrigerants, as well as pull down tests to evaluate the charge required to make the system reaching the same steady-state evaporator temperature both for R134a and R600a.

\section{REFERENCES}

[1] Calm, J.M. (2008). The next generation of refrigerantshistorical review, considerations, and outlook. Int. J. of Refrig., 31(7): 1123-1133. https://doi.org/10.1016/j.ijrefrig.2008.01.013

[2] Montreal Protocol on substances that deplete the ozone layer, United Nation Environment Program (UN), New York, NY, USA, 1987.

[3] Kyoto Protocol to the United Nation Framework Convention on Climate Change, Kyoto, JPN, 1997.

[4] Greco, A., Mastrullo, R., Palombo, A. (1997). R407C as an alternative to R22 in vapour compression plant: An experimental study. Int. J. of En. Res., 21(12): 1087-1098. https://doi.org/10.1002/(SICI)1099114X(19971010)21:12<1087::AID-ER330>3.0.CO;2-Y

[5] Greco, A., Vanoli, G.P. (2005). Flow boiling heat transfer with HFC mixtures in a smooth horizontal tube. Part II: Assessment of predictive methods. Exp. Therm. and Fluid Sc., 29(2): 199-208. https://doi.org/10.1016/j.expthermflusci.2004.03.004

[6] Greco, A., Vanoli, G.P. (2006). Experimental two-phase pressure gradients during evaporation of pure and mixed refrigerants in a smooth horizontal tube. Comparison with correlations. Heat and Mass Transfer, 42(8): 709725. https://doi.org/10.1007/s00231-005-0020-7

[7] Aprea, C., Greco, A. (1998). An experimental evaluation of the greenhouse effect in R22 substitution. En. Conv. and Man., 39(9): 877-887. https://doi.org/10.1016/S0196-8904(97)10058-9

[8] Heath, E.A. (2017). Amendment to the Montreal Protocol on substances that deplete the ozone layer (Kigali Amendment). International Legal Materials, 56(1): 193-205. https://doi.org/10.1017/ilm.2016.2

[9] Höglund-Isaksson, L., Purohit, P., Amann, M., Bertok, I., Rafaj, P., Schöpp, W., Borken-Kleefeld, J. (2017). Cost estimates of the Kigali Amendment to phase-down hydrofluorocarbons. Env. Sc. \& Pol., 75: 138-147. https://doi.org/10.1016/j.envsci.2017.05.006

[10] Fouad, W.A., Vega, L.F. (2018). Next generation of low global warming potential refrigerants: Thermodynamic properties molecular modeling. AIChE Journal, 64(1): 250-262. https://doi.org/10.1002/aic.15859

[11] Aprea, C., Cardillo, G., Greco, A., Maiorino, A., Masselli, C. (2016). A rotary permanent magnet magnetic refrigerator based on AMR cycle. Applied Thermal Engineering, 101: 699-703. https://doi.org/10.1016/j.applthermaleng.2016.01.097

[12] Aprea, C., Greco, A., Maiorino, A., Masselli, C. (2017). Analyzing the energetic performances of AMR regenerator working with different magnetocaloric materials: Investigations and viewpoints. International Journal of Heat and Technology, 35: S383-S390. https://doi.org/10.18280/ijht.35Sp0152

[13] Aprea, C., Greco, A., Maiorino, A., Masselli, C. (2020). The use of barocaloric effect for energy saving in a domestic refrigerator with ethylene-glycol based nanofluids: A numerical analysis and a comparison with a vapor compression cooler. Energy, 190: 116404. https://doi.org/10.1016/j.energy.2019.116404

[14] Aprea, C., Greco, A., Maiorino, A., Masselli, C. (2020). The employment of caloric-effect materials for solidstate heat pumping. International Journal of 
Refrigeration,

109:

$1-11$.

https://doi.org/10.1016/j.ijrefrig.2019.09.011

[15] Aprea, C., Greco, A., Maiorino, A., Masselli, C. (2018). The environmental impact of solid-state materials working in an active caloric refrigerator compared to a vapor compression cooler. Int. J. Heat Technol, 36: 11551162. https://doi.org/10.18280/ijht.360401

[16] Mohanraj, M., Jayaraj, S., Muraleedharan, C. (2009). Environment friendly alternatives to halogenated refrigerants - a review. Int. J. of Greenhouse Gas Control, 3(1): 108-119. https://doi.org/10.1016/j.ijggc.2008.07.003

[17] Bansal, P., Vineyard, E., Abdelaziz, O. (2011). Advances in household appliances - a review. Appl. Therm. Eng., 31(17-18):

$3748-3760$ https://doi.org/10.1016/j.applthermaleng.2011.07.023

[18] Brown, J.S., Zilio, C., Brignoli, R., Cavallini, A. (2014). Thermophysical properties and heat transfer and pressure drop performance potentials of hydrofluoro-olefins, hydrochlorofluoro-olefins, and their blends. HVAC\&R Research, 20(2): https://doi.org/10.1080/10789669.2013.854146

[19] Qureshi, M.A., Bhatt, S. (2014). Comparative Analysis of COP using R134a \& R600a Refrigerant in Domestic Refrigerator at steady state condition. Int. J. of Sc. \& Res., Prestige Institute of Eng. \& Sc., 3(12): 1755-1315.

[20] Aprea, C., Greco, A., Maiorino, A., Masselli, C., Metallo, A. (2016). HFO1234ze as drop-in replacement for R134a in domestic refrigerators: An environmental impact analysis. En. Proc., 101: 964-971. https://doi.org/10.1016/j.egypro.2016.11.122

[21] Aprea, C., Greco, A., Maiorino, A., Masselli, C., Metallo, A. (2016). HFO1234yf as a drop-in replacement for R134a in domestic refrigerators: A life cycle climate performance analysis. Int. J. of Heat and Techn., 34(2): S212-S218. https://doi.org/10.18280/ijht.34S204

[22] Greco, A., Masselli, C. (2020). Reduction of the greenhouse gasses emissions in refrigeration. Tecnica Italiana - Italian Journal of Engineering Science, 64(1): 30-38. https://doi.org/10.18280/ti-ijes.640107

[23] Mota-Babiloni, A., Navarro-Esbrí, J., Barragán, Á., Molés, F., Peris, B. (2014). Drop-in energy performance evaluation of R1234yf and R1234ze (E) in a vapor compression system as $\mathrm{R} 134 \mathrm{a}$ replacements. Appl. Therm. $\quad$ Eng., $71(1)$ : 259-265. https://doi.org/10.1016/j.applthermaleng.2014.06.056

[24] Mota-Babiloni, A., Navarro-Esbrí, J., Molés, F., Cervera, Á.B., Peris, B., Verdú, G. (2016). A review of refrigerant R1234ze (E) recent investigations. Appl. Therm. Eng., 95: 211-222. https://doi.org/10.1016/j.applthermaleng.2015.09.055

[25] Molés, F, Navarro-Esbrí, J., Peris, B., Mota-Babiloni, A., Barragán-Cervera, Á. (2014). Theoretical energy performance evaluation of different single stage vapour compression refrigeration configurations using R1234yf and R1234ze (E) as working fluids. Int. J. of Refrig., 44. 141-150. https://doi.org/10.1016/j.ijrefrig.2014.04.025

[26] Mota-Babiloni, A., Navarro-Esbrí, J., Barragán-Cervera, Á., Molés, F., Peris, B. (2015). Drop-in analysis of an internal heat exchanger in a vapour compression system using R1234ze (E) and R450A as alternatives for R134a. Energy, 90 : 1636-1644. https://doi.org/10.1016/j.energy.2015.06.133
[27] Aprea, C., Greco, A., Maiorino, A. (2017). An experimental investigation of the energetic performances of HFO1234yf and its binary mixtures with HFC134a in a household refrigerator. Int. J. of Refrig., 76: 109-117. https://doi.org/10.1016/j.ijrefrig.2017.02.005

[28] Aprea, C., Greco, A., Maiorino, A., Masselli, C. (2018). The drop-in of HFC134a with HFO1234ze in a household refrigerator. Int. J. of Therm. Sc., 127: 117125. https://doi.org/10.1016/j.ijthermalsci.2018.01.026

[29] Navarro-Esbrí, J., Mendoza-Miranda, J.M., MotaBabiloni, A., Barragán-Cervera, A., Belman-Flores, J.M. (2013). Experimental analysis of R1234yf as a drop-in replacement for $\mathrm{R} 134 \mathrm{a}$ in a vapor compression system. Int. J. of Refrig., 36(3): 870-880. https://doi.org/10.1016/j.ijrefrig.2012.12.014

[30] Mota-Babiloni, A., Navarro-Esbrí, J., Barragán-Cervera, Á., Molés, F., Peris, B. (2015). Analysis based on EU Regulation No 517/2014 of new HFC/HFO mixtures as alternatives of high GWP refrigerants in refrigeration and HVAC systems. Int. J. of Refrig., 52: 21-31. https://doi.org/10.1016/j.ijrefrig.2014.12.021

[31] Kopecka, M., Hegar, M., Sulc, V., Berge, J. System Drop-In Tests of Refrigerant Blends L-40, DR-7 and ARM-30a in a Trailer Refrigeration Unit Designed for R404A. Air-Conditioning, Heating, and Refrigeration Institute (AHRI) Low-GWP Alternative Refrigerants Evaluation Program (Low-GWP AREP) (Vol. 9). TEST REPORT 2013.

[32] Mendoza-Miranda, J.M., Mota-Babiloni, A., NavarroEsbrí, J. (2016). Evaluation of R448A and R450A as low-GWP alternatives for R404A and R134a using a micro-fin tube evaporator model. Appl. Therm. Eng., 98: 330-339.

https://doi.org/10.1016/j.applthermaleng.2015.12.064

[33] Fatouh, M., Abou-Ziyan, H. (2018). Energy and exergy analysis of a household refrigerator using a ternary hydrocarbon mixture in tropical environment-Effects of refrigerant charge and capillary length. Appl. Therm. Eng., $\quad 145$ : 14-26. https://doi.org/10.1016/j.applthermaleng.2018.09.008

[34] Dalkilic, A.S., Wongwises, S. (2010). A performance comparison of vapour-compression refrigeration system using various alternative refrigerants. Int. Comm. in Heat and Mass Transf., 37(9): 1340-1349. https://doi.org/10.1016/j.icheatmasstransfer.2010.07.00 6

[35] Wongwises, S., Chimres, N. (2005). Experimental study of hydrocarbon mixtures to replace HFC-134a in a domestic refrigerator. En. Conv. and Man., 46(1): 85-100. https://doi.org/10.1016/j.enconman.2004.02.011

[36] Mohanraj, M., Jayaraj, S., Muraleedharan, C., Chandrasekar, P. (2009). Experimental investigation of $\mathrm{R} 290 / \mathrm{R} 600$ a mixture as an alternative to R134a in a domestic refrigerator. Int. J. of Therm. Sc., 48(5): 10361042. https://doi.org/10.1016/j.ijthermalsci.2008.08.001

[37] Lee, Y.S., Su, C.C. (2002). Experimental studies of isobutane (R600a) as the refrigerant in domestic refrigeration system. Appl. Therm. Eng., 22(5): 507-519. https://doi.org/10.1016/S1359-4311(01)00106-5

[38] Hermes, C.J. (2015). Refrigerant charge reduction in vapor compression refrigeration cycles via liquid-tosuction heat exchange. Int. J. of Refrig., 52: 93-99. https://doi.org/10.1016/j.ijrefrig.2014.12.014 
[39] Kheiri, A., Feidt, M., Boussehain, R., Costea, M., Popescu, T. (2011). Refrigerant charge reduction: On a new design optimization criterion for compact heat exchangers. Int. J. of Refrig., 34(6): 1462-1470. https://doi.org/10.1016/j.ijrefrig.2011.04.010

[40] Zhou, W., Gan, Z. (2019). A potential approach for reducing the R290 charge in air conditioners and heat pumps. Int. J. of Refrig., 101: 47-55. https://doi.org/10.1016/j.ijrefrig.2019.02.030

[41] Akintunde, M.A. (2013). Experimental study of R134a, R406A and R600a blends as alternative to freon 12 . IOSR J. of Mech. and Civ. Eng., 7(1): 40-46.

[42] Peyyala, A. (2017). Experimental investigation of COP using hydro-carbon refrigerant in a domestic refrigerator. IOP Conference Series: Materials Science and

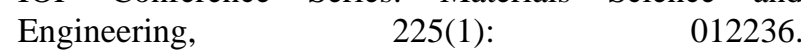
https://doi.org/10.1088/1757-899X/225/1/012236

[43] Park, K.J., Seo, T., Jung, D. (2007). Performance of alternative refrigerants for residential air-conditioning applications. Applied Energy, 84(10): 985-991. https://doi.org/10.1016/j.apenergy.2007.05.002

[44] Rasti, M., Hatamipour, M.S., Aghamiri, S.F., Tavakoli, M. (2012). Enhancement of domestic refrigerator's energy efficiency index using a hydrocarbon mixture refrigerant. Measurement, 45(7): 1807-1813. https://doi.org/10.1016/j.measurement.2012.04.002

[45] Agrawal, N., Patil, S., Nanda, P. (2017). Experimental Studies of a Domestic Refrigerator Using R290/R600a Zeotropic Blends. Energy Procedia, 109: 425-430. https://doi.org/10.1016/j.egypro.2017.03.051

[46] Sánchez, D., Cabello, R., Llopis, R., Arauzo, I., CatalánGil, J., Torrella, E. (2017). Energy performance evaluation of R1234yf, R1234ze (E), R600a, R290 and R152a as low-GWP R134a alternatives. Int. J. of Refrig., 74: 269-282. https://doi.org/10.1016/j.ijrefrig.2016.09.020

[47] Espíndola, R.S., Knabben, F.T., Melo, C., Hermes, C.J. (2019). Performance evaluation of household refrigerators running with R600a contaminated with noncondensable gases. Int. J. of Refrig. 111: 86-93. https://doi.org/10.1016/j.ijrefrig.2019.11.032

[48] Qureshi, B.A., Inam, M., Antar, M.A., Zubair, S.M. (2013). Experimental energetic analysis of a vapor compression refrigeration system with dedicated mechanical sub-cooling. Appl. En., 102: 1035-1041. https://doi.org/10.1016/j.apenergy.2012.06.007

[49] Qureshi, B.A., Zubair, S.M. (2012). The impact of fouling on performance of a vapor compression refrigeration system with integrated mechanical subcooling system. Appl. En., 92: 750-762. https://doi.org/10.1016/j.apenergy.2011.08.021

[50] Rasti, M., Hatamipour, M.S., Aghamiri, S.F., Tavakoli, M. (2011). Experimental study of R600a and R436a to replace R134a in a domestic refrigerator and freezer. In Proceedings of 7th International Chemical Engineering Congress \& Exhibition, Kish Island, Hormozgan, Iran.

[51] Pottker, G., Hrnjak, P. (2015). Effect of the condenser subcooling on the performance of vapor compression systems. Int. J. of Refrig., 50: 156-164. https://doi.org/10.1016/j.ijrefrig.2014.11.003

[52] Moffat, R.J. (1998). Describing the uncertainties in experimental results. Exp- Therm. Fluid Sci., 1(1): 3-17. https://doi.org/10.1016/0894-1777(88)90043-X 